\title{
EKSTRAKSI KONTINYU DENGAN SIMULASI BATCH TIGA TAHAP ALIRAN LAWAN ARAH: PENGAMBILAN MINYAK BIJI ALPUKAT MENGGUNAKAN PELARUT N-HEXANE DAN ISO PROPIL ALKOHOL
}

\author{
Bambang Pramudono*), Septian Ardi Widioko dan Wawan Rustyawan \\ Jurusan Teknik Kimia Fakultas Teknik UNDIP Semarang \\ Jl. Prof. Soedarto, SH, Tembalang, Semarang 50239, Telp.(024)7460058 \\ ${ }^{*}$ Penulis korenspondensi: pramudono2004@yahoo.com
}

\begin{abstract}
Abstrak
Tujuan penelitian ini adalah mengkaji rendemen dan selektivitas dari ekstraksi biji alpukat dengan pelarut n-hexane dan isopropyl alcohol (IPA). Ekstraksi dilakukan dengan sistem kontinyu simulasi batch bertahap tiga aliran lawan arah pada temperatur $82{ }^{\circ} \mathrm{C}$ (untuk pelarut $n$ - hexane) dan $69{ }^{\circ} \mathrm{C}$ (untuk pelarut IPA), selama 2 jam dengan perbandingan bahan dan pelarut sebesar $20 \mathrm{gr} / 250 \mathrm{gr}$. Rendemen yang diperoleh pada penggunaan n-hexane dan IPA sebesar 18,69 \% dan 17,87 \%. Kedua minyak yang dihasilkan baik dari penggunaan n-hexane maupun IPA memenuhi spesifikasi minyak biji alpukat. Dari besarnya rendemen yang diperoleh menunjukkan bahwa secara kuantitatif pelarut n-hexane lebih baik daripada IPA, tetapi dari segi kualitatif (kandungan impuritas) pelarut IPA lebih baik daripada n-hexane.
\end{abstract}

Kata kunci: biji alpukat, ekstraksi, rendemen, solven

\begin{abstract}
The aim of the research is to study the yield and selectivity of avocado seed extraction using n-hexane and isopropyl alcohol (IPA) as solvent. Extraction was carried out by continuous system with three stages counter current batch simulation at $82^{\circ} \mathrm{C}$ (for n-hexane) and $69^{\circ} \mathrm{C}$ (for IPA solvent) during 2 hours, the material and solvent ratio is $20 \mathrm{gr} / 250 \mathrm{~g}$. Yield of the research using $n$-hexane and IPA are $18,69 \%$ and $17,87 \%$. Both oil either using n-hexane or IPA solvent fulfills avocado seed oil specification. From the yield obtained that n-hexane is quantitatively better than IPA but the impurity content showed that IPA is qualitative better than $n$-hexane.
\end{abstract}

Keywords: avocado seed, extraction, yield, solvent

\section{PENDAHULUAN}

Alpukat disamping buahnya memiliki kandungan gizi yang tinggi, daunnya pun dapat digunakan sebagai bahan ramuan obat sakit ginjal. Biji alpukat digunakan untuk pembibitan dan berkhasiat sebagai obat sakit gigi, kencing batu, dan kencing manis. namun kebanyakan biji alpukat ini dibuang begitu saja setelah diambil buahnya. Di samping daging buahnya, biji alpukat juga memiliki potensi yaitu kandungan proteinnya tinggi dan kandungan minyaknya hampir sama dengan kedelai sehingga biji alpukat dapat dijadikan sebagai sumber minyak nabati. Berdasarkan pertimbangan bahwa buah alpukat mudah didapat, harganya murah, dan bijinya belum banyak dimanfaatkan secara maksimal, maka perlu dilakukan penelitian tentang biji alpukat tersebut.
Untuk memperoleh minyak dari biji alpukat dapat dilakukan dengan cara ekstraksi padat-cair (leaching). Dengan cara ekstraksi ini, kehilangan minyak dalam proses dapat seminimal mungkin dan kondisi operasi akan mempengaruhi kualitas dan kuantitas minyak yang dihasilkan (Salunkhe, 1992; http://www.oilsbynature.com/products/avocado-oil1.htm; Ketaren, 1986)

Penelitian ini bertujuan mengkaji rendemen dan selektivitas dari ekstraksi biji alpukat dengan pelarut n-hexane dan IPA berdasarkan analisis kimia dan fisika hasil minyak yang didapatkan, yaitu: indeks bias, density minyak, bilangan asam, bilangan penyabunan, bilangan iod, asam lemak bebas, dan rendemen. 
Faktor-faktor yang berpengaruh pada proses leaching adalah: jumlah konstituen (solute) dan distribusinya dalam padatan, sifat padatan, dan ukuran partikel. Mekanisme proses leaching dimulai dari perpindahan solven dari larutan ke permukaan solid (adsorpsi), diikuti dengan difusi solven ke dalam solid dan pelarutan solut oleh solven, kemudian difusi ikatan solut-solven ke permukaan solid, dan desorpsi campuran solut-solven dari permukaan solid kedalam badan pelarut (Treyball, 1980).

Pada umumnya perpindahan solven ke permukaan terjadi sangat cepat di mana berlangsung pada saat terjadi kontak antara solid dan solvent, sehingga kecepatan difusi campuran solut-solven ke permukaan solid merupakan tahapan yang mengontrol keseluruhan proses leaching. Kecepatan difusi ini tergantung pada beberapa faktor yaitu : temperatur, luas permukaan partikel, pelarut, perbandingan solut dan solven, kecepatan dan lama pengadukan. Untuk memisahkan minyak dari pelarutnya, dilakukan dengan cara distilasi (Treyball, 1980).

\section{METODE PENELITIAN}

Bahan yang digunakan dalam penelitian ini adalah biji alpukat yang berasal dari buah alpukat hijau pendek dengan berat 200-230 gr yang telah dihaluskan dan dikeringkan terlebih dulu. Peralatan dan rangkaian alat ekstraksi yang terdiri dari statif, klem, pendingin balik, termometer, labu leher tiga, pemanas air, dan pengaduk magnet seperti yang disajikan pada gambar 1 .

Sebelum percobaan dilakukan penyiapan bahan baku yaitu biji alpukat dikupas kulit arinya, kemudian dicuci dan dipotong-potong, dan selanjutnya dikeringkan sampai mencapai kadar air kesetimbangan (equilibrium moisture content). Setelah pengeringan usai, biji alpukat dihaluskan dengan blender dan diayak hingga mendapatkan ukuran 40 mesh, yang siap digunakan sebagai bahan kerja.

Operasi leaching dilakukan secara kontinu dengan menggunakan simulasi batch bertahap tiga aliran berlawanan. Langkah operasinya seperti yang ditunjukkan pada gambar 2 .

Langkah 1 sampai dengan 3 dianggap sebagai langkah pendahuluan karena pada ketiga langkah pertama ini hasil yang didapat masih berubah-ubah dan belum steady, sedangkan langkah 4 sampai dengan 6 adalah langkah operasi sesungguhnya, di mana diharapkan mulai langkah ke4 operasi telah berada dalam keadaan mantap atau steady state. Pada langkah pertama, biji buah alpukat dan pelarut dimasukkan sebagai umpan ke dalam ekstraktor, dan selanjutnya dilakukan proses leaching. Setelah proses leaching selesai, cairan dan padatannya dipisahkan sebagai ekstrak dan rafinat. Pada langkah kedua pelarut baru (fresh solvent) ditambahkan ke dalam ekstraktor ke- 3 di mana ekstraktor masih berisi padatan sisa pada langkah pertama. Setelah dilakukan leaching rafinat dimasukkan ke dalam ekstraktor yang ke-2, kemudian dimasukan umpan baru. Bila dalam ekstrak terdapat endapan padatan maka sebelum dianalisis dipisahkan lebih dulu dengan centrifuge. Demikian seterusnya langkah-langkah percobaan ini dilakukan sesuai dengan gambar 2 .

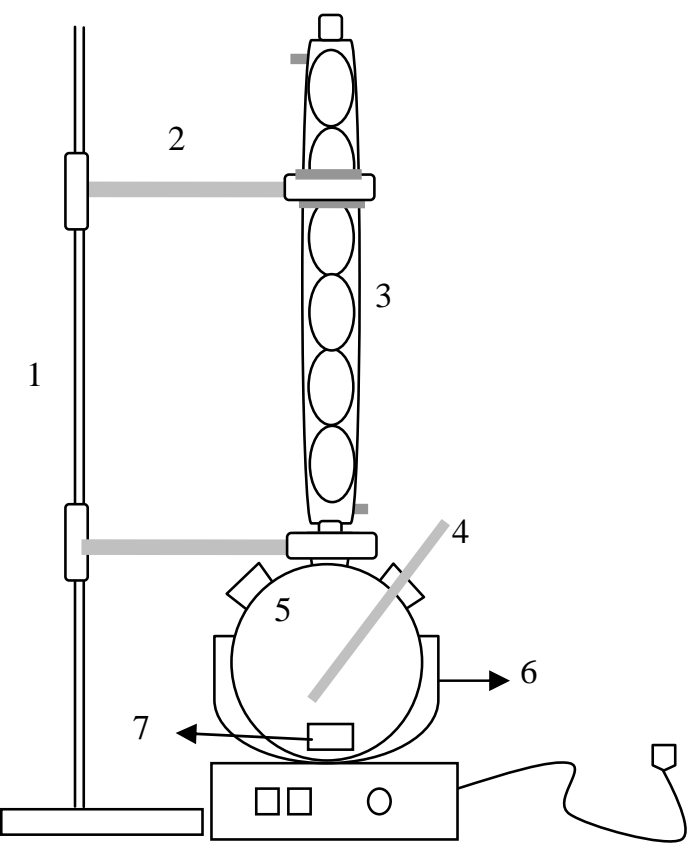

Keterangan :

1. Statif

2. Klem

3. Pendingin balik

4. Termometer

5. Labu leher tiga

6. Pemanas air

7. Pengaduk magnet

Gambar 1. Rangkaian alat ekstraksi dengan metode pengadukan biasa 
1

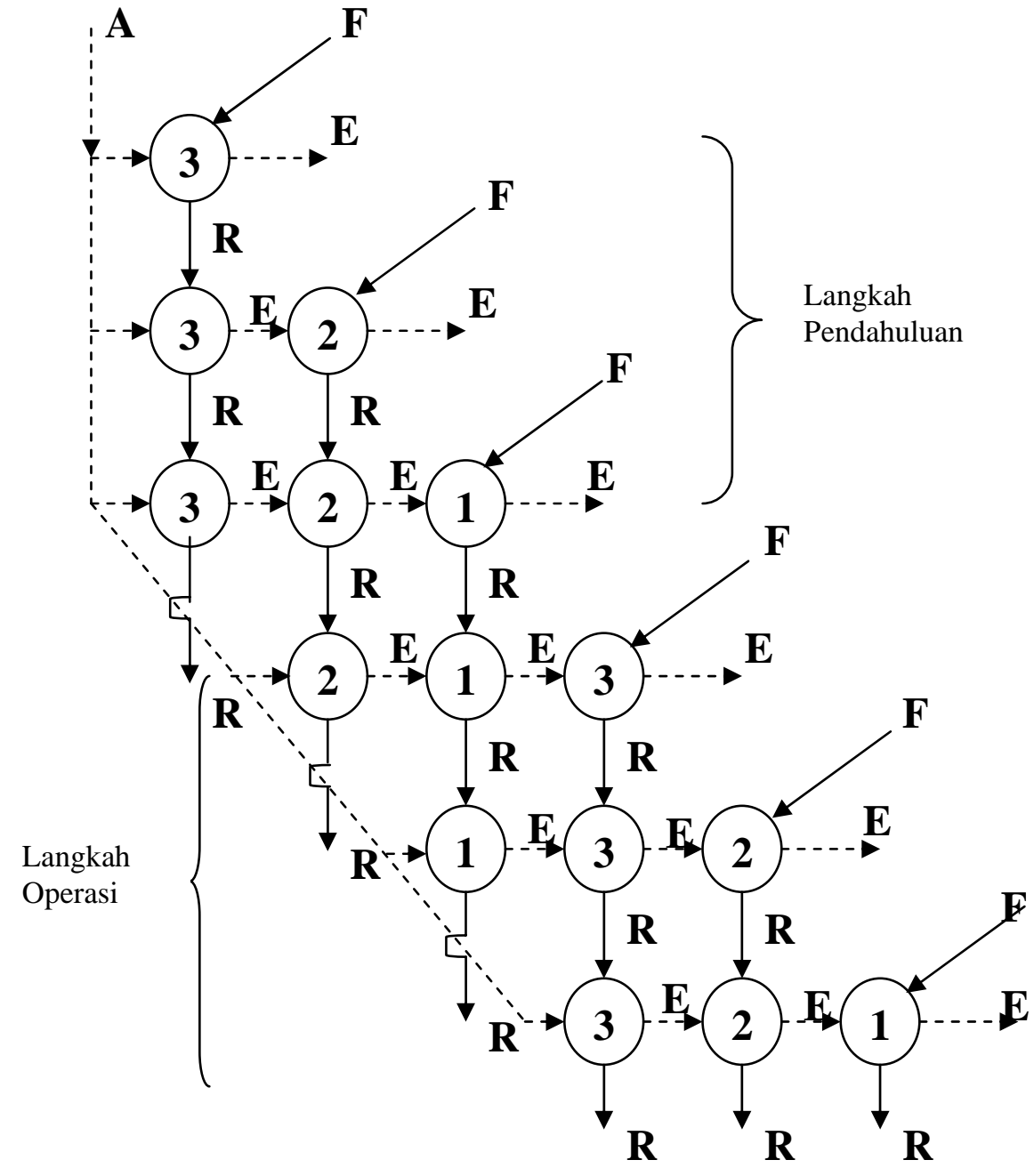

2

Keterangan :

A : Solven

E : Ekstrak

$\mathrm{R}$ : Rafinat

F : Umpan masuk (bahan yang akan diekstraksi)

Gambar 2. Operasi ekstraksi kontinyu menggunakan simulasi batch bertahap tiga dengan aliran lawan arah

(Pramudono, 1988)

\section{HASIL DAN PEMBAHASAN}

Sifat fisik (densitas dan indeks bias) dan sifat kimia (bilangan iod, bilangan asam, dan angka penyabunan) dari hasil ekstraksi dengan menggunakan pelarut n-hexane dan IPA disajikan pada tabel 1. dan data ekstraksi yang telah diolah ditunjukkan pada tabel 2.

Dari tabel 1 terlihat bahwa harga tiap langkah (langkah 1 sampai 6) pada penggunaan solven nhexane untuk masing-masing parameter tidak menunjukkan perbedaan yang berarti, sehingga dapat dianggap atau diwakili oleh harga rata-ratanya. Harga rata-rata densitas, indeks bias, bilangan asam, bilangan iod, dan angka penyabunan berturut-turut adalah 0,922 g/cc; 1,467; 0,249 mg KOH/g; 78,232 g
Iod/100 g; dan 181,896 mg KOH/g dengan standar deviasi 0,003; 0,004; 0,027; 0,997; dan 1,521. Demikian pula untuk solven IPA, harga rata-rata densitas, indeks bias, bilangan asam, bilangan iod, dan angka penyabunan berturut-turut adalah 0,912 g/cc; 1,465; 0,301 mg KOH/g; 77,243 g Iod/100 g; dan $180,383 \mathrm{mg} \mathrm{KOH} / \mathrm{g}$ dengan standar deviasi 0,006; 0,002; 0,009; 1,099; dan 1,489.

Dari analisis kimia dengan menggunakan GCMS untuk ekstrak langkah keenam untuk solven nhexane diperoleh hasil asam lemak bebas seperti disajikan pada tabel 3, dengan kandungan kimia yang dominan adalah asam oleat sebesar $71,715 \%$, asam linoleat $13,135 \%$ dan asam palmitat 6,032\%, sedangkan untuk solven IPA berturut-turut adalah 73,265\%; 15,602\%; dan 6,177\%. 
Tabel 1. Hasil ekstraksi dengan menggunakan pelarut n-hexane maupun IPA

\begin{tabular}{|c|c|c|c|c|c|c|c|c|c|c|}
\hline $\begin{array}{l}\frac{D}{2} \\
\frac{2}{0} \\
\text { क }\end{array}$ & 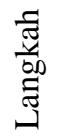 & $\begin{array}{c}\text { Bil. } \\
\text { Asam (mg } \\
\text { KOH/g) }\end{array}$ & $\begin{array}{l}\text { Bil. Iod } \\
\text { (gr Iod } \\
\text { /100g) }\end{array}$ & $\begin{array}{c}\text { Angka Penya- } \\
\text { bunan } \\
\text { (mg KOH /g) }\end{array}$ & $\begin{array}{l}\text { Berat } \\
\text { Minyak } \\
\text { (g) }\end{array}$ & $\begin{array}{l}\text { Vol. } \\
\text { Minyak } \\
\text { (ml) }\end{array}$ & $\begin{array}{l}\text { Rende- } \\
\text { men, \% }\end{array}$ & $\begin{array}{c}\text { Indeks } \\
\text { Bias }\end{array}$ & $\begin{array}{l}\text { Density } \\
(\mathrm{g} / \mathrm{ml})\end{array}$ & $\begin{array}{l}\text { Selekti } \\
\text {-vitas } \\
(\%)\end{array}$ \\
\hline \multirow{6}{*}{ D. } & 1 & 0,266 & 77,605 & 179,880 & 3,6221 & 3,95 & 18,11 & 1,463 & 0,917 & \multirow{6}{*}{84,850} \\
\hline & 2 & 0,225 & 77,765 & 180,136 & 3,6826 & 3,99 & 18,41 & 1,465 & 0,914 & \\
\hline & 3 & 0,235 & 77,885 & 182,065 & 3,7341 & 4,05 & 18,67 & 1,466 & 0,913 & \\
\hline & 4 & 0,244 & 79,051 & 183,007 & 3,7720 & 4,10 & 18,86 & 1,475 & 0,920 & \\
\hline & 5 & 0,202 & 77,067 & 184,225 & 3,9396 & 4,25 & 19,70 & 1,470 & 0,927 & \\
\hline & 6 & 0,279 & 80,021 & 177,865 & 3,9562 & 4,30 & 19,78 & 1,466 & 0,920 & \\
\hline \multirow{6}{*}{ 岕 } & 1 & 0,310 & 75,665 & 178,889 & 3,1429 & 3,45 & 15,74 & 1,465 & 0,911 & \multirow{6}{*}{88,867} \\
\hline & 2 & 0,306 & 76,085 & 180,775 & 3,8846 & 4,25 & 19,42 & 1,463 & 0,914 & \\
\hline & 3 & 0,289 & 78,775 & 177,865 & 3,1956 & 3,55 & 15,98 & 1,463 & 0,913 & \\
\hline & 4 & 0,311 & 77,055 & 181,202 & 3,6450 & 4,00 & 18,23 & 1,466 & 0,910 & \\
\hline & 5 & 0,299 & 77,765 & 181,805 & 3,7597 & 4,10 & 18,80 & 1,469 & 0,917 & \\
\hline & 6 & 0,288 & 78,115 & 181,761 & 3,8134 & 4,15 & 19,07 & 1,465 & 0,919 & \\
\hline
\end{tabular}

Tabel 2. Data olahan hasil ekstraksi

\begin{tabular}{cccccc}
\hline \multirow{2}{*}{ No } & \multirow{2}{*}{ Parameter } & \multicolumn{2}{c}{ n-hexane } & \multicolumn{2}{c}{ IPA } \\
\cline { 3 - 6 } & & Rata-rata & $\begin{array}{c}\text { Standar } \\
\text { deviasi }\end{array}$ & Rata-rata & $\begin{array}{c}\text { Standar } \\
\text { deviasi }\end{array}$ \\
\hline 1 & Berat jenis (gr/ml) & 0,922 & 0,003 & 0,912 & 0,006 \\
2 & Indeks bias & 1,467 & 0,004 & 1,465 & 0,002 \\
3 & Bilangan asam (mg KOH/gr) & 0,249 & 0,027 & 0,301 & 0,009 \\
4 & Bilangan iod (gr Iod/100gr) & 78,232 & 0,997 & 77,243 & 1,099 \\
5 & Angka penyabunan (mg KOH/gr) & 181,896 & 1,521 & 180,383 & 1,489 \\
\hline
\end{tabular}

Tabel 3. Hasil analisis kimia minyak biji alpukat

\begin{tabular}{cccc}
\hline No & Kandungan kimia & n-hexane $(\% \mathrm{w} / \mathrm{w})$ & IPA $(\% \mathrm{w} / \mathrm{w})$ \\
\hline 1 & oleic acid & 71,715 & 73,265 \\
2 & linoleic acid & 13,135 & 15,602 \\
3 & palmitic acid & 6,032 & 6,177 \\
4 & stearic acid & 1,530 & 1,248 \\
5 & lauric acid & 0,164 & 0,132 \\
6 & myristic acid & 0,700 & 0,733 \\
7 & palmitoleic acid & 0,606 & 0,633 \\
8 & margaroleic acid & 0,017 & 0,044 \\
9 & fenolat & 0,972 & 0,292 \\
10 & aldehid & 1,450 & 0,942 \\
11 & chlorofil & 1,306 & 0,910 \\
12 & riboflavin & 0,701 & - \\
13 & keton & 1,672 & 0,022 \\
\hline
\end{tabular}


Bila hasil tersebut dibandingkan dengan data dari literatur yang menyatakan bahwa spesifikasi minyak biji alpukat yang meliputi densitas 0,91$0,925 \mathrm{gr} / \mathrm{cc}$; indeks bias 1,46-1,48; bilangan asam < 0,5; bilangan Iod 75-95 dan angka penyabunan 180195; kandungan asam oleat $60-80 \%$, asam linoleat 10-20\%; asam palmitat $4-10 \%$ maka dapat disimpulkan bahwa hasil minyak yang didapat dari ekstraksi yang menggunakan solven n-hexane maupun IPA termasuk ke dalam spesifikasi minyak biji alpukat, sehingga boleh dipastikan bahwa minyak hasil ekstraksi tersebut adalah minyak biji alpukat (Apriyantono, dkk, 1989).

Data hasil percobaan yang hampir sama juga ditandai dengan kecilnya standar deviasi menunjukkan bahwa pada saat langkah pertama bukan lagi sebagai langkah pendahuluan melainkan sudah langkah operasi yang steady. Hal ini disebabkan karena selektivitas solvent terhadap minyak yang cukup tinggi.

Dari kelima parameter hasil ekstraksi, untuk indeks bias, bilangan iod, dan angka penyabunan dari penggunaan IPA dan n-hexane dapat dianggap sama. Untuk parameter densitas, hasil ekstraksi menggunakan solven n-hexane memiliki densitas yang lebih tinggi yaitu 0,922 gr/ml dibanding 0,912 gr/ml pada IPA. Densitas yang lebih tinggi ini disebabkan oleh persentase impuritas (fenolat, aldehid, keton, chlorofil, dan riboflavin) pada penggunaan n-hexane lebih besar. Untuk parameter bilangan asam, hasil ekstraksi menggunakan IPA memiliki bilangan asam yang lebih tinggi yaitu 0,301 mg $\mathrm{KOH} / \mathrm{gr}$ dibanding 0,249 $\mathrm{mg} \mathrm{KOH} / \mathrm{gr}$ pada nhexane. Hal ini disebabkan komponen asam lemak dari hasil ekstraksi dengan menggunakan IPA lebih besar dibanding hasil ekstraksi yang menggunakan nhexane, sehingga $\mathrm{KOH}$ yang diperlukan untuk menetralkan asam lemak yang terdapat dalam minyak juga lebih banyak.

Untuk perbandingan rendemen, tabel 1 menunjukkan bahwa rendemen ketika menggunakan solven n-hexane lebih besar daripada rendemen jika menggunakan IPA. Hal ini dikarenakan n-hexane tidak hanya mengestrak minyak tetapi juga terdapat senyawa lain yang terikut di antaranya fenolat, aldehid, klorofil, riboflavin, dan keton dimana senyawa-senyawa tersebut kadarnya lebih besar daripada senyawa-senyawa yang sama yang terekstrak oleh IPA. Bahkan n-hexane mampu mengestrak riboflavin, sedangkan IPA tidak. Riboflavin adalah senyawa vitamin B2 dimana dalam alpukat sendiri kaya akan vitamin B2. Selain itu bila ditinjau dari sifatnya bahwa minyak biji alpukat bersifat non polar karena memiliki rantai carbon yang cukup panjang dari asam lemak dan bersifat hidrofobik sedang n-hexane juga bersifat non polar sehingga minyak biji alpukat dapat terekstrak dengan baik. Untuk senyawa IPA mempunyai dua buah sisi dimana sisi pertamanya bersifat polar yakni $\mathrm{CHOH}$ dan sisi yang lain bersifat non polar yaitu $\mathrm{CH}_{2} \mathrm{CH}_{3}$, sehingga hal inilah yang membuat IPA mampu mengestrak minyak biji alpukat, karena dia memiliki bagian yang bersifat non polar seperti minyak biji alpukat yang juga bersifat non polar.

Secara kualitatif rendemen hasil ekstraksi dengan menggunakan solven n-hexane lebih tinggi daripada menggunakan solven IPA, tetapi kandungan impuritasnya juga lebih seperti kadar keton nya $1,672 \%$, di manapersyaratan keton pada minyak pangan harus seminim mungkin bahkan kalau bisa dihilangkan. Keton ini mempunyai efek negatif yaitu bila kandungannya dalam darah dan urin manusia tinggi menyebabkan hypoglisemia yang berakibat hyperinsulin atau menimbulkan ketidak harmonisan metabolisme dan ketoasidosis yang berujung pada penyakit diabetes mellitus. Inilah yang menyebabkan kenapa secara kuantitatif hasil yang diperoleh menggunakan n-hexane lebih bagus tapi bila dari segi kualitatif IPA lebih baik.

\section{KESIMPULAN}

Berdasarkan hasil ekstraksi dengan menggunakan pelarut n-hexane dan IPA dapat disimpulkan beberapa bahwa ditinjau dari rendemen yang diperoleh, proses ekstraksi minyak secara kuantitatif lebih bagus menggunakan n-hexane sebagai solven karena rendemen yang diperoleh lebih tinggi. Ditinjau dari selektivitas (kadar asam oleat dan asam linoleat), proses ekstraksi minyak secara kualitatif lebih bagus menggunakan IPA karena kadar asam oleat dan asam linoleat lebih tinggi. Selain itu pada minyak hasil ekstraksi menggunakan IPA kadar bahan berbahaya (keton) lebih rendah.

\section{DAFTAR PUSTAKA}

Salunkhe, D.K., (1992), “World Oilseeds”, Van Nostrand Reinhold, New York.

http://www.oilsbynature.com/products/avocado-oil1.htm

Ketaren, S., (1986), “Pengantar Teknologi Minyak dan Lemak Pangan”, UI Press, Jakarta.

Treyball, R.E., (1980), “Mass Transfer Operations”, McGraw-Hill Book Company, New York.

Pramudono, B., (1988), "Petunjuk Praktikum Operasi Teknik Kimia Leaching”, Jurusan Teknik Kimia Fakultas Teknik Universitas Diponegoro, Semarang.

Apriyantono, A., Fardiaz, D., Puspitasari, N. L., Sedarnawati, dan Budyanto, S., (1989), ”Analisis Pangan”, IPB Press, Bogor. 